\title{
Televisión, Telenovelas y la \\ Construcción del Conocimiento en las Sociedades Contemporáneas.
}

\begin{abstract}
Uno de los temas de gran interés en las Ciencias Sociales se refiere a los modos y formas de producción y de reproducción del conocimiento social. En este contexto, muchos estudios se han dedicado a analizar cómo las diversas instituciones contribuyen a construir la cohesión, la integración social y el sentido de unidad, a partir de ciertos conocimientos que permiten a los individuos sentirse y reconocerse como parte de una determinada sociedad o grupo social.
\end{abstract}

La atención en este artículo se focaliza en una institución en especial, la televisión, y en cómo ella participa, por medio del género telenovela, en el proceso de producción y de reproducción del conocimiento compartido socialmente. En este sentido, se aborda el proceso de consolidación de esta institución en el contexto social, y se discute cómo la televisión y las telenovelas, de acuerdo con sus características, colaboran para la construcción y la reproducción de los conocimientos utilizados para el desarrollo del proceso de socialización de los telespectadores.

Uno de los temas de gran interés en las Ciencias Sociales se refiere a los modos $\mathrm{y}$ formas de producción $\mathrm{y}$ de reproducción del conocimiento social. En este contexto, muchos estudios se han dedicado a analizar cómo las diversas instituciones contribuyen a construir la cohesión, la integración social y el sentido de unidad, a partir de ciertos conocimientos y saberes que permiten a los individuos sentirse $y$ reconocerse como parte de una determinada sociedad o grupo social. Entre las instituciones más activas en las últimas décadas, la televisión siempre ha generado polémica por algunos de los tipos de actividades que desarrolla, y ha suscitado controversia por la forma cómo se cree que interfiere en la construcción de la mentalidad y de la manera de ver el mundo y la vida de los sujetos contemporáneos. Entre los más variados géneros que conforman lo que es hoy día la televisión, los géneros populares atraen particularmente la atención en este sentido, principalmente por el hecho que, todavía, son considerados como amenazadores o disonantes del bagaje cultural y cognitivo visto como legítimo para orientar los futuros desarrollos de la vida social. Entre los más significativos y mundialmente famosos géneros populares presentes en lo que es actualmente la televisión, las telenovelas se han posicionado entre los productos culturales preferidos por el público receptor, pero poco se sabe, todavía, sobre como colaboran, dentro de un conjunto, a la formación y construcción de los saberes que son utilizados como herramientas de vida por los sujetos sociales.

Entre los aspectos problemáticos que han complicado la profundización de este tema, esta, primero, la fatiga por aceptar el rol ejercido por la televisión como una de las agencias que contribuyen significativamente a la formación de lo que es la sociedad hodierna. Segundo, la dificultad de
Márcia Gomes Márquez es socióloga de la PUC del Rio de Janeiro, Master en Maestría en Comunicación Social en la Universidad Javeriana de Bogotá y el Ph.D en Ciencias Sociales en la Universitá Gregoriana, Roma. Su especialidad es la Teoría de la Comunicación, con énfasis en los estudios de recepción con relación a los géneros populares, área en la cual ha sido profesora y ha publicado artículos en revistas especializadas y en congresos. 
reconocer la importancia de productos populares en la configuración de las percepciones de los individuos, y de problematizar la visión establecida de que los productos populares sirven exclusivamente para "divertir". Como parte importante de lo que es la actual versión de televisión, el punto que aquí se plantea es que las telenovelas contribuyen a la formación social de sus telespectadores. Se propone, en este sentido, que para entender cómo ellas efectivamente contribuyen a forjar lo que es y lo que será de la sociedad contemporánea, no sólo se debe considerar lo que dicen los productores/emisores sobre estos productos, sino además desplazar el centro de la atención al encuentro de los telespectadores con estos programas.

De este modo, este artículo se concentra en una institución en especial, la televisión, y en cómo ella participa, por medio del género telenovela, en el proceso de producción y de reproducción del conocimiento compartido socialmente. Se aborda el proceso de consolidación de esta institución en el contexto social, y se discute cómo la televisión y las telenovelas, de acuerdo con sus características, colaboran en la construcción y la reproducción de los conocimientos utilizados para el desarrollo del proceso de socialización de los telespectadores.

\section{Los medios y la vida social}

Desde el avenimiento de la televisión, en pocas décadas ella se convirtió uno de los principales medios de conexión y de comunicación de los individuos entre sí, de ellos con la sociedad en general, y también de los diferentes grupos sociales $y$ sociedades, tanto dentro de las fronteras nacionales y regionales, como en el ámbito de las diferentes naciones $\mathrm{y}$ regiones del mundo. La rápida difusión $\mathrm{y}$ posicionamiento de este medio de comunicación responde a una serie de factores, entre los cuales se puede decir que el desarrollo tecnológico en el sector de las telecomunicaciones
- y la intensificación de la urbanización desempeñan un rol determinante. A ellos se suman otros cambios que sucedieron $o$ se intensificaron también el siglo $\mathrm{XX}$, como el desarrollo industrial — la proletarización y la producción en cadena - y la elevación de los niveles de escolarización, que también incidieron considerablemente en el rol que los medios de comunicación en general, y la televisión en particular, pasaron a ocupar dentro de la vida social.

Los factores que caracterizaron el último siglo fueron decisivos en lo que se refiere a la difusión practica $y$ técnica de los medios y al desarrollo de nuevas formas de organización de la vida social y cultural de las sociedades. La contextualización de los medios de comunicación en las sociedades de esto siglo es fundamental y necesaria, pues se deben situar espacio-temporalmente para hablar de ellos como un fenómeno planetario: es a partir de ahí, entonces, que uno se debe ubicar para referirse a sus usos, al como entran a ser parte de la vida de las personas, y de como pasan a conectar histórica y geográficamente las comunidades de los diversos continentes.

Las transformaciones que caracterizaron este último siglo fueron acompañadas por grandes cambios en el ámbito institucional. Se amplió la presencia del Estado en los diversos sectores sociales, pasando a actuar también como promotor del sistema escolar (preparación de mano de obra calificada para el sector industrial) y del desarrollo de los medios de comunicación, como herramienta para estimular e impulsar la integración y la defensa de los territorios nacionales. La institución familiar también cambió considerablemente a lo largo del último siglo. La vida en la ciudad, el predominio de la estructura nuclear, la inserción de las mujeres en el mercado del trabajo, la proletarización y la difusión del acceso a la escuela, entre otras cosas, han hecho que, al nivel de organización, de gestión y de alcance, 
el papel de la familia, y su relación con las otras instituciones (como los medios de comunicación o la escuela), fuera reformulado y redimensionado.

Los cambios en la vida de los individuos e de los grupos sociales fueron considerables sea a nivel microsocial (la vida en el barrio, las rutinas familiares, la inserción de los individuos en el mercado de trabajo) que a nivel macrosocial, en lo que se refiere, por ejemplo, a los tipos de relación que los individuos mantienen con las diferentes instituciones. De hecho, la nueva configuración de la sociedad implica profundos cambios en la gestión de la vida social. La administración de la vida cotidiana, la formación de las nuevas generaciones y la integración de los individuos en la comunidad, son todos aspectos que fueron necesariamente revisados con el emerger de la sociedad dinámica del siglo $\mathrm{XX}$.

En una sociedad que cambia permanentemente, en la que los individuos pueden y deben "ajustarse" constantemente a una diversidad de nuevas situaciones y de modificaciones estructurales, se intensifica la velocidad de adquisición y la variedad del repertorio de informaciones y de habilidades que se necesitan para insertase y "seguir" la dinámica social. En este cuadro, la cuestión de la formación y de la "construcción" de los sujetos sociales, o sea, la socialización adquiere una importancia fundamental, principalmente cuando si toma en consideración que, actualmente, los individuos son preparados no solamente para seguir, sino también para promover las transformaciones que se verifican.

En el contexto mencionado los medios de comunicación pueden ser vistos y evaluados no solamente como un espacio de diversión para llenar el tiempo considerado libre, sino principalmente como una de las instituciones sociales que aporta nuevos elementos y actualiza el repertorio de conocimientos de que los sujetos disponen para interactuar socialmente. Más aún, entendiendo la socialización como un proceso en el cual los individuos construyen la propia identidad social a partir de la interacción con la sociedad, los medios pueden también ser analizados como un espacio privilegiado en el cual los individuos encuentran elementos para realizar una apropiación tanto del mundo que les circunda cuanto de sí mismos (de sus identidades), a partir de la identificación/diferenciación de la representación del "otro" (personas y contextos sociales) ofrecida por los medios.

\section{Los medios de comunicación como institución social}

En términos generales, los medios de comunicación han adquirido una importancia sin precedentes por el hecho que vinculan, de una $u$ otra manera, gran parte de la población en las sociedades contemporáneas. Con el crecimiento de su ámbito de acción y la regularidad de las actividades que desempeñan, conquistaron expectativas por parte del público relacionadas a la estabilidad de su estructura, de su forma y de los roles que asumieron. En otras palabras, los medios de comunicación de masas se institucionalizaron, siendo el reconocimiento de esta dimensión imprescindible para situarlos - y en especial a la televisión — en las relaciones sociales de poder. Más aún, como afirma Orozco Gómez, «the separation between TV as institution and TV as medium is inappropriate and impossible since TV as an outcome of technical development is also the result of a political-technological process within a particular social milieu. TV cannot be conceived of only as a medium ${ }^{1}{ }^{1}$.

En términos generales, algunas de las características más importantes de los medios de comunicación como institución social son: 1) que producen y distribuyen conocimientos; 2) que proveen canales que permiten la comunicación entre las personas; 3) que operan casi exclusivamente en la esfera pública; 4) que la participación de las personas en las actividades que promueven es voluntaria; 5) que están vinculados al mercado y a la industria
(01) OROZCO GÓMEZ, G.: "Research on cognitive effects of non-educational televisión: an epistemológical discussion», en DRUMMOND, P.y PATERSON, $R$.: Television and its Audience. Intemational Research Perspectives, British Film Institute, London,1988, pp. 225. 
(02) Cfr. MCQUAIL, D.: Le Comunicazioni di Massa, II Mulino, Botogna, 1993, pp. 49-50. (03) Cfr. BRANSTON, G., «TVas institution: strategies for teaching", en Screen, vol. 25, $n^{\circ}$ 2, 1984, pp. 88-89; Cfr. ELUS, J.: Visible Fictions, Routledge and Kergan Paul, London, 1982. (04) Cfr. MARTELU, S.: «Bassa definizione. Nuovi media, istituzioni educative e processi socio-culturali nella postmodemitàn, en MARTELU, Stefano: Videosocializzazione. Processi educativi e nuovi media, Franco Angeli, Milano, 1996. (05) Jensen y Rosengren definen como "pánico moral" el miedo que, principalmente a traves de sus contenidos, los medios puedan influenciarnegativamente a las clases de personas identificadas como sendo menos capazes de defenderse. Ver, JENSEN, KB. y ROSENGREN,

$K E$ : "Five traditions in search of the audiencen, European Joumal of Communication, vol. 5, $n^{\circ}$ 2-3, 1990, pp. 208-209.

(06) PORRO, R.: «Educazione scolastica e sistema del median,, en CRESPI, Franco: Sociologia e Cultura: nuovi paradigmi teorici" e metodi di ricerca nello studio dei processi culturali, Franco Angeli, Milano,1989. por la dependencia de financiamiento, mano de obra y desarrollo tecnológico; 6) que están relacionados al poder por los vínculos que poseen con el Estado y con la sociedad civil ${ }^{2}$. Si el discurso se desplaza de los medios en general a la televisión como institución, considerando sus especificidades en el tipo de actividad que realiza, se pueden destacar las siguientes características: 1) que su señal es accesible a cualquiera que posea o arriende un aparato de televisión y que es recibido en ambiente doméstico; 2) que su imagen es de pequeña escala, de baja definición y que la utilización del sonido es crucial para alertar y mantener la atención de los usuarios; 3) que ella procura mantener un flujo constante de transmisión; 4) que su programación es construida por formas abiertas/cerradas, con unidades de segmentos cortos, de algunos minutos de duración, que captan tajadas de atención ${ }^{3}$.

Relacionadas a las características institucionales mencionadas, los medios de comunicación desempeñan una serie de funciones y de actividades ligadas a la formación social, entre las cuales se pueden resaltar la informativa, la comunicativa, la de entretener, la de producción y de reproducción cultural, la de socialización y la de legitimación política, ideológica y económica ${ }^{4}$. La actuación de los medios $\mathrm{y}$, específicamente, de la televisión como agencia e institución ligada a la formación social, sin embargo, es permeable a una serie de polémicas que se refieren, por un lado, a la relación de esta con las otras instituciones sociales "especializadas" en la función formativa, y por otro lado, a la dificultad de cohesión de las informaciones y de los valores que ella transmite. La falta de coherencia interna en los mensajes de los medios se debe, en parte, al conflicto oriundo del des-encuentro entre las varias potencialidades y finalidades de uso que los medios de comunicación poseen y ofrecen. Esta cuestión se toma aún más problemática dependiendo de la interpretación que se hace sobre el poder (y el deber) del Estado y de la sociedad civil de reglamentar y coordinar la formación de las jóvenes generaciones.

3. La televisión y las otras agencias de formación social

Parte de las acusaciones y polémicas referentes a la actuación de la televisión como institución involucrada en la formación social, se debe a la atribución de interferencia o de apropiación indebida de ciertas responsabilidades y funciones que se presuponían dominio exclusivo de instituciones como la familia o la escuela. Esto sucede porque se juzga que la televisión produce "rumor" al tipo de educación que la familia o la escuela procuran dar a las jóvenes generaciones $^{5}$. A la raíz del conflicto, está la lucha por la definición de la realidad que cada una de las diversas agencias sociales ofrecen: la televisión entrega su versión (plural y en muchos casos contradictoria), la que, muchas veces, no sintoniza por completo con las que son aceptadas por las otras agencias. Cuando la diversidad se presenta, se cuestiona, entonces, la legitimidad de los medios para ofrecer alternativas a lo que es planteado por otras agencias en el ámbito de la educación y formación social.

De modo general, la relación existente entre los diversos ámbitos de formación y de socialización fue tradicionalmente considerada competitiva, y cualquier posibilidad de continuidad entre escuela y medios de comunicación sistemáticamente nega$\mathrm{da}^{6}$. Los mecanismos que caracterizan el proceso de formación y de socialización fueron, y continúan siendo vistos, como vehículos de transferencia de un patrimonio cognitivo y cultural consolidado en favor de los "nuevos" miembros de la comunidad. En esta perspectiva, el aparato escolar es visto como la institución depositaria de un universo de valores y de normas de comportamiento compartidos socialmente; mientras que la televisión, por lo contrario, representa un espacio de transgresión, portadora de imperativos 
$y$ de sugerencias extrañas o alejadas (cuando no opuestas) al patrimonio cultural más consolidado.

Algunos autores apuntan a que parte del crecimiento de la acogida de la televisión como ámbito de socialización se debe al hecho de que la familia ha disminuido su acción, en frecuencia e intensidad, con relación a las nuevas generaciones 7 . El espacio dejado libre por el debilitamiento de la actividad educativa en el ámbito doméstico habría sido, por consiguiente, ocupado por la televisión ${ }^{8}$. Danziger relaciona la disminución de la importancia de la familia en el proceso general de socialización al proceso de modernización y de industrialización en larga escala, y afirma que «Laddove la divisione del lavoro non è associata alla struttura della parentela, i nuclei parentali sono impotenti a preparare l'individuo ad affrontare importanti aspetti della vita adulta» ${ }^{9}$.

Los límites en la actuación formativa de la familia, con relación a la educación común y a la educación especializada (a ser impartidas respectivamente por la escuela y por el ambiente laboral) fueron también indicados por Durkheim. Para este autor, sea por la afirmación de la división del trabajo, sea por la crisis en que la familia se encuentra a partir de las transformaciones sociales, o porque en ella priman las relaciones educativas de tipo particularistas y afectivas, esta institución no está más en grado de desarrollar de forma general una acción formativa en la sociedad industrial ${ }^{10}$.

La competencia entre las diversas agencias puede ser vista en términos del tipo de conocimiento que cada cual ofrece, y del tipo de saber que se requiere para efectuar la integración de los sujetos en el medio social. En este sentido, Williams afirma que los medios vinieron a llenar las exigencias y las necesidades que, en una sociedad más dinámica las instituciones tradicionales no lograban satisfacer ${ }^{11}$. Según este autor, estas instituciones se encargaban con eficacia de transmitir ideologías u órdenes aisladas, pero no poseían estructura para cumplir con otras peticiones de la nueva configuración social, o sea, informaciones, noticias, previsiones y actualizaciones permanentes. Añade que una conciencia creciente de la movilidad y de la transformación, no solamente en abstracto, sino también como experiencia vivida, llevó a una grande redefinición, en la practica y después en la teoría, de las funciones y del proceso de comunicación social.

Los medios de comunicación y la televisión, en particular, son llamados a contestar, por lo tanto, a las demandas $\mathrm{y}$ exigencias que surgen con el desarrollo de una sociedad más dinámica, que por tal característica, pide una serie de conocimientos que no se encuadran por completo en lo que es el patrimonio cultural y cognitivo consolidado que las instituciones tradicionales ofrecen. De esta manera, la potencialidad de oferta de noticias, de informaciones y de novedades posibilitó el gran desarrollo que la televisión tuvo en el último siglo, al paso que condicionó el modo en que esta se desarrollo.

4. Televisión y potencialidades operativas

A la televisión se le pueden atribuir diversas potencialidades, objetivos, usos o utilidades, dependiendo de la perspectiva a partir de la cual se la examina: si esta es evaluada desde el punto de vista del público, de los emisores, del Estado, de la sociedad civil. McQuail, por ejemplo, construye tipologías distintas para las funciones y los usos atribuidos a los medios de comunicación por la sociedad y por el público receptor ${ }^{12}$. Entre las finalidades potenciales de los medios para la sociedad, resalta la capacidad de informar, de entretener (divertir, reducir la tensión y evadir), de correlacionar (crear consenso, establecer órdenes de prioridades), de promover el sentido de continuidad y de movilizar. Para la audiencia, los aspectos más importantes estarían relacionados al uso de los medios como fuente de información, de
(07) CESAREO, V.: Socializzazione e Controllo Sociale. Una critica dell'uomo ultrasocializzato, F. Angeli, Milano, 1994.11a ed.

(08) SECCO, L: «La pedagogia di fronte ai mass median, en MARTEU, S.:

Videosocializzazione. Processi educativi e nuovi media, Franco Angeli, Milano, 1996. (09) DANZGER, K. La Socializzazione, II Mulino, Bologna, 1979, pp. 120. (10) DURKHEM, É: Educazione come Socializzazione, La Nuova Italia, Firenze, 1973. (11) Cfr. WLLAMS, R.: Televisione. Tecnologia e forma culturale, De Donato, Baní, 1981, pp. 52-57. (12) McQUAIL, D.: Le Comunicazioni di Massa, 84-87. 
(13) Sobre las diferentes opciones nacionales de desarrollo de la televisión ligadas a los intereses comerciales (privada) y aquellas más estrechamente vinculadas al "interés publico", Williams dice que, independientemente de cuales sean «i controlli pubblicie i criteri politici vigenti, le istituzioni hanno come loro scopo primario la realizzazione e la distribuzione di profitti privati sul capitale investito equesto influenza visibilmente le loro scelte principalis. WUAMS, $R$.: Televisione, 76. Porotro lado, aún que las redes de televisión pública tengan como finalidad atender al "interés público", surge la cuestión fundamental de definir ¿cuál es el interés público?, que se vincula a quienes-cuales grupos - tienen la posibilidad y la autoridad para decidir en nombre de todos los otros. identidad personal (valores y modelos de comportamiento), de interacción, de integración social (como apoyo en el desempeño de los roles sociales y fuente de temáticas para conversar) $\mathrm{y}$ de entretenimiento. Las finalidades del uso de la televisión para la sociedad planteadas por McQuail presentan varios puntos de contacto con las actividades formativas, educativas $\mathrm{o}$ socializadoras, como es el caso: de explicar, interpretar y comentar el significado de los eventos y de las informaciones (correlación); de gestionar la adhesión a la autoridad constituida y a las normas (correlación); de expresar la cultura dominante y de reconocer las subculturas y los nuevos desarrollos culturales (continuidad); de proveer informaciones sobre los eventos y las condiciones de la sociedad y del mundo (información); de indicar las relaciones de poder (información); de favorecer la socialización (correlación).

Estas capacidades son indicativas del tipo de uso que se puede hacer de la televisión, pero no ofrecen límites conclusivos para que se afirme que la televisión se reduce a la suma de estas "utilidades" o potencialidades operativas, o que cada una de ellas se manifieste con la misma frecuencia o intensidad. En otras palabras, no existe una correlación directa entre lo que se puede hacer con la televisión y el contenido que es efectivamente promovido por los emisores, o consumido por los telespectadores. La jerarquía o el grado de prioridad de las capacidades de la televisión depende, principalmente, de las expectativas $\mathrm{y}$ del uso que realmente se ha hecho de ella, sea por los emisores que por los receptores. Se vincula, también, con lo que realmente interesa y es viable (del punto de vista económico, político y social) de ser transmitido a través de su programación. Más aún, a pesar de ser posible, como abstracción, separar las diversas utilidades o propiedades operacionales desempeñadas por la televisión, estas se sobreponen, se presentan en conjunto y muchas veces, incluso, entran en conflicto, por ejemplo, cuando apuntan principalmente a la reproducción/conservación social (continuidad), mientras que otras promueven la transformación/innovación social (información). A diferencia de la institución escolar, que como fue dicho anteriormente reafirma el patrimonio cultural consolidado, la televisión circula-juega entre la repetición y la novedad, entre la conservación y la transgresión. Además de eso, contrariamente otra vez a como es la institución escolar (que se propone a trabajar principalmente con la "realidad"), la televisión, en su versión actual, lo hace sea con la realidad que con la ficción (fantasía), a veces por separado, a veces al mismo tiempo. De este modo, además de hablar sobre como es, o de proponer una versión sobre como son las cosas, la televisión abre también espacio para la discusión de como podría o debería ser, abriéndose también a la fantasía, a la crítica, al deseo y a la creatividad.

La apertura a la discusión entre los diversos proyectos de sociedades, entre la iniciativa de transformar y de reproducir, y el confronto entre lo "real" y lo "imaginario" depende, sin embargo, del modelo y del tipo de televisión que se ha desarrollado en cada país, de la apertura que en ésta se ha dado a la participación social, y de los límites que las diversas sociedades colocan (implícita o explícitamente) a la posibilidad de que los cambios se manifiesten pública y abiertamente.

5. La programación televisiva y la jerarquía de los usos operacionales

En la configuración actual de la televisión brasileña y de muchos otros países centro y sudamericanos, el modelo político y económico adoptado, en combinación con otros factores, colaboraron para que el desarrollo de la televisión diera prioridad a la iniciativa privada por sobre la pública ${ }^{13}$. Esta configuración posibilita el desarrollo de una producción orientada predominantemente a una programación destinada al tiempo libre, a la concepción de los medios como promotores de diversión y de 
entretenimiento para las audiencias.

El funcionamiento de la televisión privada es fuertemente condicionado al hecho de que ella depende de los niveles de audiencia para vender los espacios publicitarios, o sea, para autofinanciarse. En este sentido, la planificación de la programación busca, en primera instancia, atender y atraer un mayor número posible de telespectadores, y es así que el objetivo central de los productores en la televisión comercial es la popularidad. En esta óptica, los telespectadores son considerados desde dos aspectos complementarios relacionados con su capacidad de consumo: en cuanto consumidores de productos/programas (ofrecidos por las emisoras), y como consumidores de productos/mercancías (vendidos por la publicidad, por el merchandising y por los programas de teleshopping).

La configuración de lo que se ofrece a los telespectadores, en consecuencia, expresa esta relación triangular (también de dependencia) entre el público, los anunciantes y las emisoras. El reconocimiento de la importancia del público en esta relación y la forma como las emisoras pretenden atraerlos introducen una serie de elementos que interfieren, entre otras cosas, en la jerarquía con que cada una de las potencialidades operacionales mencionadas anteriormente se manifiestan en la selección y organización de la programación televisiva. Resaltar esta relación de dependencia no equivale a afirmar que el momento del consumo, visto como el espacio de circulación y de apropiación de mercancías, tiene el poder de dictar unilateralmente las reglas de la oferta. Esto equivaldría a continuar dentro de una visión polarizada de las relaciones de producción que separa estrictamente el momento de consumo de aquel de la producción. Afirmar que la oferta televisiva se construye en la relación entre productores y consumidores, por el contrario, significa reconocer el feedback que existe entre las partes, tanto en el momento de elaborar los productos/mercancías ${ }^{14}$, cuanto en el momento de consumirlos y de apropiarlos.

Además, la producción y recepción/consumo de los programas ofrecidos están contextualizados no sólo desde las características políticas y económicas de las sociedades donde la televisión se desarrolla, sino dependen también de las especificidades sociales y culturales de cada sociedad, pues es un encuentro de factores sociales, políticos, culturales y económicos, tanto del público como de los productores, que posibilitan que se produzcan una determinada configuración de la producción y de la oferta televisiva.

\section{La televisión y los géneros televisivos} En un estudio sobre la programación disponible en la televisión brasileña, Morales e Lobo clasificaran la oferta televisiva dentro de las siguientes categorías: informativa, entretenimiento/ficción, y especial; determinando que, en aquel momento, estas tres categorías correspondían a 25,48 y $26 \%$ del total de las transmisiones de los canales abiertos de televisión ${ }^{15}$. En la categoría informativa fueron incluidos los reportajes, las entrevistas, los programas de servicios, los noticieros generalísticos y los noticieros especializados en deportes, en temas culturales y en noticias policiales. A la categoría entretenimiento/ficción correspondían las películas, los seriados, las miniseries, las telenovelas, los talk shows, los programas de variedades, de humor, de deportes, de música y otros. La categoría "especial" contemplaba: los programas infantiles, religiosos, educativos, culinarios, teleshoppings y otros.

En la primera categoría, como se puede observar, el eje es la potencialidad informativa, aún que los diversos tipos de programas agrupados combinan en diferentes medidas la información al entretenimiento, a la educación, a la movilización de la audiencia, a la promoción del consenso, etc. El eje conductor de la segunda categoría es
(14) A propósito de ver los programas televisivos como productos/mercancias, Thorbum afirma que rart is always a commodity of some kind, constrained by the technology necessary to its production and by the needs of the audience for which it is intendeds. Cfr.

THORBURN, D., «Television melodraman,,", en NEWCOMB, $H$.: Television: the crittcal view,

Oxford University Press, New York, 1987, pp. 633.

(15) La medición fue hecha en octubre de 1994, con un total de 1001h. e 21m, comespondientes a las transmisiones efectuadas por la Rede Globo, la Bandeirantes, la SBT, la Manchete, la Record, la Cultura y la CNT/Gazeta. MORALES, O.ET. y LOBO, N.J.F., "A hegemony da telenovela (Estudo preliminar da programação televisiva brasileira)"y, INTERCOM, vol. XIX, $n^{\circ} 1,1996, p p .107-120$. 
(16) Crf.. MAZZOTT, N.: "Acercamientosa las telenovelas latinoamericanas", en FADUL, A.: Ficção Seriada na TV, ECA-USP, São Paulo, 1993, pp. 25. Crf., también, MATTELART, M. $y$ MATIELART, A.: O Camaval das Imagens. A ficção na TV, Brasiliense, São Paulo, 1989, pp. 25, 43.

(17) Figaro, por ejemplo, ofrece un cuadro detallado de las exportaciones de las telenovelas brasileñas para otros países latinoamericanos e para la América del norte; Bustos Romero, porsu vez, indica que as exportações de telenovelas mexicanas para diversos países americanos e europeus, para a China e os países Árabes amontavam, em 1993, a 24.000 horas de programação por ano; Traquina, también, presenta algunos datos interesantes sobre la presencia de estos productos en Portugal, Crf. FIGARO, R.A., "La telenovela brasileña en el mercado intemacionalı, en Estudios sobre las Culturas Contemporàneas, vol. III, $n^{\circ} 6$, época ll, 1997, pp. 33-47; cfr. BUSTOS-ROMERO, O.: "Gender and mass media in México: the receptors of soap operas», en FADUL, A.: Ficção Senad́a na TV, ECA-USP, São Pauto, 1993, pp. 124; cfr. TRAQUINA, N., "Tendências da televisão portuguesa na nova era da concorrênciaun, en INTERCOM, vol. $X X, n \%$ I, 1997, pp. 13-31.

(18) Crf. SOUSA, M.W. de: "Jovens e a telenovela: seduções da vida cotidiana", en PACHECO,

E. Dias: Comunicação, Educaçãoe Arte na Cultura Infanto-Juvenil, Loyola, São Pauto, 1991, pp. 91. la capacidad/objetivo de entretener; y reúne programas de ficción (películas), otros que no son de ficción (deportes) y otros aún que no son necesariamente de ficción (talk shows, programas de humor). Los programas específicamente de ficción (películas, seriados, telenovelas, miniseries) representaban $23 \%$ de la programación en el periodo de tiempo investigado. En esta categoría, también, cada tipo de programa combina, con otras funciones o utilidades, la de informar, de educar, de correlacionar eventos y significados, de proveer un sentido para los acontecimientos, de promover el consenso, etc.

Aparte organizar los tipos de programas presentes en la televisión brasileña en tres grandes y amplias categorías, este estudio dispone también algunos datos significativos de lo que es la televisión brasileña. Por ejemplo, indica que el $72 \%$ de los programas eran de producción nacional, y que la Red Globo y a la SBT $\left(1^{\circ}\right.$ e $2^{\circ}$ colocadas en el rating de audiencia) correspondían respectivamente 51 y $22 \%$ de la producción ficcional de la televisión brasileña. Estos números son indicativos del tipo de televisión que se ha hecho en las últimas décadas en Brasil, pero no logran dar una clara visión de conjunto por no considerar también la relación existente con los otros dos aspectos del triángulo de dependencia mencionado anteriormente. Confrontar estos datos con los que provienen del público (quienes, cuando y como) y de los anunciantes significa, por ejemplo, ponderarlos de acuerdo con los horarios de transmisión, con los índices de audiencia que poseen, y con el valor que tienen para la publicidad los distintos horarios de la programación.

Un ejemplo bastante significativo de como puede cambiar la representatividad de estos números cuando se toma en cuenta los otros factores, se puede encontrar en la comparación de los diferentes géneros de ficción dentro del cuadro de la programación de la Rede Globo. Los films, que en la medición indicada ocupaban el $23 \%$ de la programación de esta emisora, son transmitidos, en general, por las tardes, en las últimas oras de la noche y de madrugada. Las telenovelas, por otro lado, representan el $14 \%$ de sus transmisiones, pero son transmitidas de lunes a viernes por la tarde, y de lunes a sábado de las 18 a las 22h., aproximativamente. Considerando además los números referentes a la audiencia, los índices de las telenovelas giran con frecuencia alrededor de 40 a 50 puntos en el prime-time, o sea, en el horario de más alto valor comercial dentro de la programación diaria.

La importancia de este género para la industria cultural de los países latinoamericanos, de modo general, ha sido resaltada en diversos estudios ${ }^{16}$. Respecto a su presencia en el mercado internacional, varios trabajos en las últimas décadas la han documen-tando ${ }^{17}$. Datos, como los aportados por Sousa, indican en adición que en un país como Brasil el $75 \%$ de la población ve telenovela diariamente $^{18}$, acentúan también la relevancia de este producto no solamente desde el punto de vista económico, pero también como un fenómeno social y cultural de primera grandeza.

La constatación de la hegemonía de este género en la producción ficcional latinoamericana, y su amplia difusión en muchas partes del mundo, abre espacio a una serie de preguntas. La primera que se podría hacer es ¿por qué este género no pasa desapercibido? Otro aspecto que surge es la disposición de querer ubicar los factores que explican el grande éxito de público de las telenovelas. La propagada y poco insignificante presencia de estos programas instiga, consecuentemente, el interés en identificar ¿cuales son las características de estos productos que justifican una semejante acogida por parte de los telespectadores?

\section{Telenovela y usos}

El interés por individuar las causas del grande éxito de las telenovelas hace que se busque identificar y comprender por qué este género en especial logra conquistar la atención del público 
consumidor. Un primero factor, que se puede indicar a partir de las categorías planteadas por Morales y Lobo, es que la telenovela tiene como objetivo predominante entretener, y que es una ficción. Al nivel de sentido común, esta es la explicación más habitual que es dada al fenómeno telenovelas. Pero si esto fuera suficiente para explicar su éxito, se podría esperar que todos los productos de ficción que entretienen/ divierten tengan el mismo éxito de audiencia. Como, de hecho, esto no se verifica, cabe entonces preguntarse si, aparte de los dos aspectos ya identificados, este género posee otros potenciales usos o capacidades comunicativas que contribuyan significativamente a su notoriedad y grande apelo popular.

Una forma de identificar las especificidades características de las telenovelas desde la perspectiva del género en sí mismo, es la de establecer la combinación que este presenta de las diferentes capacidades y potencialidades comunicativas antes mencionadas. Con relación a la dimensión informativa, por ejemplo, las telenovelas tratan prioritariamente temáticas que se refieren a las relaciones cotidianas de los grupos sociales que giran alrededor de la vida privada de los individuos, de la familia, de la comunidad; ellas hablan sobre las rutinas diarias que articulan y expresan diferentes formas de combinar los valores y las costumbres en las practicas sociales concretas. Comparando los temas de las telenovelas con los que son planteados por los noticiarios (dirigidos a hacer "saber que"), se puede afirmar que en ellos la atención se concentra en los sectores mas "altos" de la estructura social, en los acontecimientos de excepción y en los eventos públicos ${ }^{19}$. Las telenovelas, en cambio, enfocan la vida privada, dramatizan el cotidiano, las motivaciones de los individuos y los hábitos sociales, y representan principalmente la vida de personas "comunes" que difícilmente ven sus vidas "retratadas" por los noticieros, o por los programas de debate $o$ de entrevistas. En este sentido, se puede decir que la dimensión informativa también está presente en las telenovelas, aún que exista una diferencia substancial en el tipo del contenido tratado, y en la forma de narrar la información.

La telenovela presenta diferentes puntos de contacto con los programas clasificados en la categoría "especiales". A diferencia de los programas de teleshopping, por ejemplo, en donde el énfasis es puesto principalmente en el aspecto comercial (a través de la venda en directa), en las telenovelas la promoción de los productos se da en forma indirecta, a través del merchandising $\mathrm{y}$ en las frecuentes pausas hechas para los anuncios publicitarios. Por otra parte, los programas educativos mencionados en la categoría "especial" son aquellos que, según Williams, transfieren a la televisión las formas de organización - como la conferencia, la lección y la demostración - y los tipos de contenidos típicos de la clase $\operatorname{escolar}^{20}$. Las telenovelas se diferenciarían de ellos substancialmente, tanto en el modo de organizar la narrativa, cuanto en las propuestas del contenido didáctico y en el tipo de relación que se establece entre el público receptor y el programa. Las telenovelas, sin embargo, se acercan a la definición que hace Williams de la televisión educativa en sentido general $^{21}$, ya que presentan diferentes modos de conducir la vida (privada), exponen una diversidad de condiciones sociales (a través de los personajes), y representan distintas formas de relacionar la esfera privada con el mundo del trabajo. Más que instruir directamente acerca de las características o etapas constitutivas, ellas "ofrecen" experiencias sobre el proceso, por ejemplo, de vivir en sociedad.

En cuanto a los programas "religiosos", estos buscan sensibilizar, introducir o reafirmar las convicciones de los telespectadores con relación a un determinado conjunto de creencias, sea por la presentación de un ritual, o a través de argumentaciones específicas. Las telenovelas se diferencian de este tipo de programa de modo amplio,
(19) Cfr. MURDOCK, M., «Fabricando ficciones: elementos para el estudio de la producción e dramas televisivos», Estudio sobre las Culturas Contemporáneas, vol. II, $n^{\circ} 4-5$, 1988, pp. 68.

(20) Cfr. WLWAMS, $R$. Televisione, 98.

(21) Crf. WLUAMS, $R$, Televisione, 125. 
tanto en la organización narrativa y en la especialización de las ideas tratadas, cuanto en la intencionalidad de persuadir o sensibilizar sobre un conjunto de ideas determinadas. Esto no significa, sin embargo, que el contenido de las telenovelas no involucre ideas de tipo religioso: por lo contrario, la representación de situaciones de carácter religioso (como parte de la vida privada de las personas) es corriente en las telenovelas, pero estas representaciones no tienen, necesariamente, el objetivo de convencer o persuadir los telespectadores.

Todos los textos narrativos pueden utilizar varios tipos de recursos disponibles, pero la elaboración de un texto que hace parte de un determinado género es marcada por el uso de ciertos códigos y estructuras de sentido. Serán estos mismos los encargados de garantizar no solamente la presencia de algunos elementos, sino también su centralidad dentro de los textos narrados. En los programas inscritos dentro da lógica dos géneros se debe mirar cuáles son estos elementos comunes que, a partir de los núcleos temáticos, de la trayectoria típica de los personajes centrales y de la forma recurrente de construir la narrativa, pueden ayudar a comprender el tipo de interacción cognitiva que tiene mayores posibilidades de establecerse a partir del contacto texto-receptor $y$, además, proporcionar una idea sobre el estoque de sentido y el modelo de mundo propuesto por ellos. De este modo, la atracción ejercida por las telenovelas puede depender tanto de los contenidos de las historias que cuentan, como de la forma de combinar estos contenidos y de organizar la narrativa. Más aún, puede depender de las características del género como tal, y de cómo éstas se organizan en relación con las especificidades técnicas del medio televisión.

Esas dimensiones de las telenovelas, en conjunto con las potencialidades anteriormente mencionadas, hablan principalmente sobre cómo es este género televisivo, sobre lo qué es transmitido a través de él, y sobre cuales son sus características potenciales. Este tipo de análisis sería suficiente para explicar por qué las personas ven telenovela, y qué hacen con lo que ven, dentro de una tradición donde se parte del presupuesto que el sentido es inherente a la obra, y que, por lo tanto, es en ella misma donde se deben buscar las explicaciones al impacto que ejercen sobre los receptores. Este tipo de postura, sin embargo, minimiza el rol de la audiencia en el proceso comunicativo. Además, no toma realmente en consideración que la recepción constituye un espacio privilegiado de lucha por la definición, y por la redefinición de la realidad social.

Este trabajo maneja una concepción diversa de aquella que, como dice Lindlof, entiende que la producción de sentido es controlada por los diversos elementos objetivos del contenido y por las agencias que lo elabora (presented meaning)22. Aquí se sostiene que para evaluar la construcción social del sentido es necesario averiguar lo que sucede a partir del encuentro de las telenovelas con las teleaudiencias. Es decir, se propone que, a partir del análisis de lo que sucede en el encuentro entre género/producto y audiencia, se puede evaluar no solamente el potencial latente del género, sino también aquel efectivo, que es el que se realiza de hecho $y$ concretamente. Según el enfoque adoptado, para entender el éxito y las consecuencias sociales de este género, es necesario desplazar el eje desde la discusión exclusiva sobre el texto y ubicarlo en el cruce entre el texto y la audiencia.

\section{Las Telenovelas: un género de "entretenimiento"}

La división de los productos televisivos en ciertas categorías y la clasificación de las telenovelas como un género de entretenimiento, ayudan a entender ciertos aspectos de estos programas, como la jerarquía de "funciones" o de utilidades que priman, según la intencionalidad de los productores, en los diferentes tipos de 
programación. Este tipo de clasificación está centrado en la intencionalidad de los emisores/ productores, y no toma directamente en cuenta a los telespectadores en la definición/clasificación que es hecha de estos productos. Los programas presentados en la televisión son, de este modo, clasificados por sus propiedades "inherentes", y cabe al telespectador tener suficiente sensibilidad o capacidad para reconocer y atenerse a estas propiedades ${ }^{23}$ : cualquier lectura divergente es, en esta óptica, aberrante. Desde esta perspectiva, un programa es educativo, o el público "puede" aprender de él, cuando es elaborado con la intencionalidad de enseñar. En otras palabras, el uso que se puede hacer de un programa está condicionado por sus propiedades inherentes/intrínsecas, construidas y delimitadas intencionalmente por los productores. Asi, las telenovelas "deben" ser utilizadas para divertirse, y cualquier uso que no corresponda a eso será, por lo tanto, una "aberración".

La clasificación de las telenovelas como "programación de entretenimiento" es aún más problemática o menos adecuada, si por entretenimiento se entienden solamente los aspectos fugaces, inconsecuentes y superficiales del placer, de la evasión y de la diversión. El énfasis exclusivo en los aspectos efímeros y frívolos restringe la dimensión y la complejidad de lo qué es y de cómo es vivido el descanso y el uso del tiempo libre en las sociedades contemporáneas. El acento en las consecuencias superficiales de este tipo de programación, además, sintoniza con un tipo de visión que considera la televisión apenas como un medio de transmisión (de señales, de símbolos, de informaciones, de datos), y que descuida los aspectos estéticos, culturales y sociales de la interacción que el público tiene con ella.

Una visión más amplia de lo que puede ser la "diversión” y el "entretenimiento" presentes en la interacción con programas como las telenovelas, puede ser desarrollada a partir de las propuestas de Turner sobre la análisis de los aspectos rituales de la representación, de la actuación, de la performance $y$ de la interacción cultural $^{24}$. En ese tipo de abordaje es posible identificar las representaciones ofrecidas por los géneros ficciones (como las telenovelas) como "metacommenti sociali", como espejos activos que analizan los axiomas y los presupuestos de la estructura social y que, por el contacto visceral que mantienen con la estructura cultural y simbólica, generan espacios de frontera, limítrofes y de confín, entre lo que es la "realidad" y lo que es la fantasía. A ese respecto, por ejemplo, según Turner,

«i cosiddetti generi 'di
intrattenimento' della società industriale sono spesso sovversivi, cioè satireggiano, prendono in giro, mettono alla berlina o corrodono sottilmente i valori centrali della sfera del lavoro su cui si fonda la società, o almeno di settori particolari di quest'ultima. Fra parentesi, la parola "intrattenere", entertain, deriva dall'antico francese entretenir, "tenere separato", cioè creare uno spazio liminale o liminoide nel quale le performance possano aver luogo»». ${ }^{25}$

En la medida que se rescata la dimensión de limen, de brecha, de umbral y de transición entre estos dos dominios, Turner acentúa también la dimensión cultural y reflexiva del acto de entretener $\mathrm{y}$ de entretenerse, enfatizando los aspectos creativos y activos de transitar, de representar, de contemplar, de imaginarse y de reconocerse en la representación.

«In una cultura il 'significato' viene di solito generato nelle interfaces tra $\mathrm{i}$ sottosistemi cultural i riconosciuti, anche se poi l'istituzionalizzazione e il consolidamento dei significati avviene nella zona centrale di tali sistemi. La liminalità é una interface temporale, le cui proprietà costituiscono il parziale capovolgimento di quelle dell' ordinamento già consolidato su cui si fonda qualsiasi 'cosmos' culturale specifico.» ${ }^{26}$

Rescatar los aspectos que posibiliten una visión menos reducida y simplista de lo que hay de placentero
(23) A ese propósito, Newcombe Hirsch mencionan que muchos investigadores y críticos de televisión asumen que el público debería entender los programas del mismo modo con que ellos entienden; cuando eso no sucede, el diagnóstico es que el público es incapaz de evaluar correctamente $y$, porconsecuencia, debería aceptar el juzgamiento hecho por quienes tienen competencia (técnica y cientitfica) para hacerlo. Cfr. NEWCOMB, HyHIRSCH, P.: "Television as a cultural forum. Implications forresearch", en W. ROWLAND, W. yWATKINS, B.: Interpreting Television: current research perpectives, Sage, Beverty Hills, 1984, 59.

(24) Cfr. TURNER, V.: Dal Rito al Teatro, II Mulino, Bologna, 1986.

(25) TURNER, V.: Dal Rito al Teatro, pp. 81.

(26) TURNER, V.: Dal Rito al Teatro, pp. 82 
(27) Cfr. McQUAIL, D.: Le Comunicazioni di Massa, pp. 8689.

(28) Cfr. ROBERTS, D., $y$ SCHRAMM, W.: "Children's learning from the mass mediaun, en SCHRAMM W., y ROBERTS, D.: The Process and Effects of Mass Communication, University of Illinois Press, Chicago, 1977, pp. 600-601. $4^{a} \mathrm{ed}$.

(29) inhat may be leamed from the pictorial media is often very significant Fantasy content contains a great deal of Information which may be important to the child. Dramas, mysteries, and situation comedies include information about customs, norms, attitudes, and role behavior. This material about what to expect from the social world are facts which children need to- and do-leam.». ROBERTS, $D$., y SCHRAMM, W.: "Children's learning from the mass median, 606.

(30) Cfr. KAPLUN, M.: «Elestudio de la recepción: un área prionitaria de investigación-acción ante los nuevos desafíos», en MELO, J.M. de: Comunicación Latinoamericana: desafíos de la Investigación para el siglo XX, ALAIC/ECA-USP, São Pauto, 1992. y de evasión en la recepción, permite recuperar lo que hay de productivo y de activo en el contacto con estos programas. De este modo, aunque se insista en enfatizar solamente las dimensiones de estos productos culturales que son admitidas y aceptadas por el sentido común, es decir, que las telenovelas sirven y deben ser usadas "solamente" para entretenerse y para divertirse, se puede, aún así, reconocer lo que hay de reflexivo, de productivo y de potencialmente subversivo en la construcción de significado y de sentido social, en el acto de "divertirse" y de "gozar" los momentos de frontera y de transición ofrecidos también por géneros populares como las telenovelas.

\section{El público y el género telenovela}

De acuerdo con los aportes hechos por la corriente de estudios de los Usos y Gratificaciones, McQuail, como se mencionó anteriormente, indica diversas posibilidades de uso o de motivaciones que conducen las personas a seguir lo que es ofrecido por los medios de comunicación: la búsqueda de información, de entretenimiento y de elementos/contenidos que contribuyan a la integración, a la interacción social y a la elaboración de la propia identidad personal ${ }^{27}$. Roberts y Schramm, desde la misma corriente de estudios y también con relación al público receptor, afirman que el empleo de los medios como fuente de información, de entretenimiento — también mencionados por McQuail - y un tercer factor, su utilidad social (ofrece la oportunidad para reunirse), serían las tres principales razones que explicarían los usos de la televisión por parte de los niños ${ }^{28}$. Advierten, sin embargo, que programas que usualmente no son clasificados como informativos, pueden ser considerados así por los receptores. Ejemplifican señalando que los niños clasifican la televisión educativa como "cuadrada", como algo que los adultos han decidido que es bueno para ellas, pero que de hecho aprenden muchas veces a partir de lo que ven en los programas comerciales y en los programas clasificados como de entretenimiento. Para estos autores, lo que puede ser aprendido de los medios pictoriales es frecuentemente muy significativo. Los contenidos de fantasía contienen mucha información que puede ser importante para el niño. Dramas, misterios y programas de -humor incluyen informaciones acerca de las costumbres, normas, actitudes y modos de comportamiento. Este material sobre lo que esperar del mundo social es algo que de hecho los niños necesitan realmente aprender. ${ }^{29}$

En la tipología presentada por McQuail o en los motivos de consumo televisivo propuestos por Roberts $\mathrm{y}$ Schramm, el público receptor es visto como un conjunto de individuos que, en el contacto con la televisión, buscan determinadas características en la programación que satisfagan sus necesidades o expectativas personales (subjetivas o objetivas). En esta visión, que enfatiza la búsqueda de gratificaciones por parte de los telespectadores, los usos están condicionados por las características de la programación, que de acuerdo con el formato y el contenido que transmiten, ofrecen respuestas a los diferentes tipos de anhelos y demandas. Como en un supermercado, el "cliente" selecciona y adquiere el producto que, por sus características objetivas e intrínsecas, satisfagan mejor sus expectativas.

También enfatizando el punto de vista de los receptores, Kaplún sugiere que un importante instrumento operativo para el estudio de la recepción es el reconocimiento de los diferentes "modos de uso" — "telepasión", "televisión-telón-de-fondo", y "televisión-tapa-agujeros" — que se expresan en las diferentes formas de contacto o de interacción del público con lo que es presentado por la televisión ${ }^{30}$. A diferencia del abordaje de McQuail y de Roberts y Schramm, al proponer estos tres modos de usar, el autor reconoce la importancia de las características de la programación, y una cierta autonomía a los receptores, en la medida que resalta como 
elementos que juegan un rol decisivo en los modos de uso o en los tipos de consumo televisivo, la relevancia de los gustos, de los códigos culturales y de los factores de ecología social.

Además de considerar la autonomía de uso por parte de los telespectadores, otros trabajos o corrientes de estudio ven el análisis de los usos de la televisión principalmente desde una perspectiva social. De esta manera, por ejemplo, en lugar de centrarse en las opciones individuales de los consumidores, se opta por tener como unidad de análisis la familia, y se verifica a partir de ahí cuáles son los aspectos que caracterizan los usos sociales de la televisión y de los diferentes tipos de programas que componen su palimpsesto ${ }^{31}$. En lugar de centrar el eje del análisis sobre los individuos, esa otra perspectiva prioriza el aspecto social de los usos de la televisión a través de la contextualización del consumo televisivo. De este modo, se desplaza el eje del análisis desde aquello que propone el medio hacia la audiencia contextualizada, y se exploran las múltiples potencialidades de uso del medio y de sus géneros desde el punto de vista también de los usuarios. Al desplazar el lugar del problema, cambia también la pregunta que se quiere responder: en este caso, cómo las audiencias apropian y resignifican los medios y los mensajes dentro de sus practicas sociales concretas. Además de recuperar el lugar de la audiencia en el proceso comunicativo, se va desde la concepción de la comunicación como transmisión de mensajes/informaciones, a la noción de comunicación como construcción social del sentido. Este otro tipo de abordaje del contacto entre el público y los productos de los medios recupera, de cierta forma, la relativa autonomía y la autoridad que tienen las audiencias no solamente de usar, sino también de jerarquizar las características y de participar en la definición de lo qué son y para qué sirven los programas que ellas consumen.

Este desplazamiento permite, por ejemplo, cuestionar la definición reducida de las telenovelas como programación de entretenimiento, en el sentido limitado del término, pues esta clasificación es oriunda de un tipo de análisis que se centra prioritariamente en las razones y en el punto de vista de los emisores, de los productores y de los analistas y "expertos". Centrando la definición de los productos exclusivamente en este "lado" del proceso comunicativo, no se reconoce, o se menosprecia, el espacio de las audiencias en el proceso comunicativo, y su autoridad, como parte en ese proceso, de participar en la definición de los programas que ven. A la luz del desplazamiento, la cuestión que se propone es invertir el foco de la discusión: o sea, en lugar de explicar y catalogar las personas a partir de los programas que ellas ven, se propone comprender y explicar los programas, y en particular el género telenovela, también partiendo de la lectura y de la percepción que de ellos hacen sus receptores.

\section{Consideraciones finales}

El argumento de este artículo se refiere, en líneas generales, a la importancia conquistada por los medios de comunicación que, institucionalizándose, pasaron a compartir con otras instituciones la responsabilidad de producir, reproducir y distribuir el sentido y el conocimiento socialmente compartido. De modo específico, la atención se centra principalmente sobre la televisión, con la finalidad de reflexionar sobre como ella participa, también a través del género telenovela, en el proceso de producción y reproducción del conocimiento y de la construcción del sentido social, por medio de los cuales viabiliza la interacción y la integración de los sujetos en la sociedad.

Se sostiene que para entender lo que son actualmente las telenovelas es necesario hacer un doble movimiento de análisis, considerando sea los productos inscritos en este género y lo que de ellos dicen sus productores y emisores, como también los usos que de ellos hacen los telespectadores. En la visión aquí propuesta sobre el rol desempeñado por las telenovelas
(31) Cfr. LULL, J.: «The social uses of televisiónn, en WHITNEY, D.Charles, $y$ WARTELA, $E$. Communication Review Yearbook 3, Sage, Beverty Hills, 1982, 397409. Cfr., también, MARTíN BARBERO, Jesús, y MUÑOS, Sonia, coord., Televisióny Melodrama. Géneros y lectura de la telenovela en Colombia, Tercer Mundo Editores, Bogotá, 1992 
dentro de lo que es actualmente la televisión, la función social de estos programas podría ir mucho más allá de ser un simple momento en la jomada donde uno se desconecta de los problemas relevantes de la sociedad actual. Esta interpretación de las telenovelas se vincula a un tipo de visión que simplifica y reduce la significatividad social de los "momentos de descanso", al enfatizar exclusivamente lo que puede haber de superfluo y de efímero en el placer, en el entretenimiento y en la distracción. La propuesta aquí formulada es que más que "simplemente distraer", los momentos disfrutados con las telenovelas pueden, de muchos modos, contribuir al cumplimento de los roles y funciones de formación social que la televisión, como un todo, desempeña.

\section{Bibliografía do Artigo}

BRANSTON, G. TV as institution: strategies for teaching, en Screen, vol. 25, $\mathrm{n}^{\circ} 2,1984$.

BUSTOS-ROMERO, O. Gender and mass media in México: the receptors of soap operas, en FADUL, A. Ficção Seriada na TV, ECA-USP, São Paulo, 1993.

CESAREO, V.: Socializzazione e Contrallo Sociale. Una critica dell'uomo ultrasocializzato, F. Angeli, Milano, $11^{\text {a }}$ ed, 1994.

DANZIGER, K. La Socializzazione, Il Mulino, Bologna, 1979.

DURKHEIM, É. Educazione come Socializzazione, La Nuova Italia, Firenze, 1973.

ELLIS, J.: Visible Fictions, Routledge and Kergan Paul, London, 1982.

FIGARO, R.A. La telenovela brasileña en el mercado internacional, en Estudios sobre las Culturas Contemporàneas, vol. III, nº 6, época II, 1997.

JENSEN, K.B. y ROSENGREN, K.E. Five traditions in search of the audience, European Journal of Communication, vol. 5, n 2-3,1990.

KAPLUN, M. EI estudio de la recepción: un área prioritaria de investigaciónacción ante los nuevos desafíos, en MELO, J.M. de: Comunicación Latinoamericana: desafíos de la investigación para el siglo XXI, ALAIC/ECAUSP, São Paulo, 1992.

LINDLOF, T. Media audience as interpretive communities, en ANDERSON, J.A. Communication Yearbook 11, Sage, Beverly Hills, 1988.

LULL, J. The social uses of television, en WHITNEY, D. Charles, y WARTELLA, E. Communication Review Yearbook 3, Sage, Beverly Hills, 1982.

MARTELLI, S. Bassa definizione. Nuovi media, istituzioni educative e processi socio-culturali nella post-modernità, en MARTELLI, Stefano: Videosocializzazione. Processi educativi e nuovi media, Franco Angeli, Milano, 1996.

MARTÍN-BARBERO, Jesús, y MUÑOS, Sonia, coord., Televisión y Melodrama. Géneros y lectura de la telenovela en Colombia, Tercer Mundo Editores, Bogotá, 1992. 
MATTELART, M. y MATTELART, A. O Carnaval das Imagens. A ficção na TV, Brasiliense, São Paulo, 1989.

MAZZIOTTI, N. Acercamientos a las telenovelas latinoamericanas, en FADUL, A. Ficção Seriada na TV, ECA-USP, São Paulo, 1993.

McQUAIL, D. Le Comunicazioni di Massa, Il Mulino, Bologna, 1993.

MORALES, O.E.T y LOBO, N.J.F. A hegemony da telenovela (Estudo preliminar da programação televisiva brasileira), INTERCOM, vol. XIX, $n^{\circ} 1$, 1996.

MURDOCK, M. Fabricando ficciones: elementos para el estudio de la producción e dramas televisivos, Estudio sobre las Culturas Contemporáneas, vol. II, $\mathrm{n}^{\circ} 4-5,1988$.

NEWCOMB, H y HIRSCH, P. Television as a cultural forum. Implications for research, en W.ROWLAND, W. y WATKINS, B. Interpreting Television: current research perpectives, Sage, Beverly Hills, 1984.

OROZCO GÓMEZ, G. Research on cognitive effects of non-educational television: an epistcmological discussion, en DRUMMOND, P.y PATERSON, R. Television and its Audience. International Research Perspectives, British Film Institute, London, 1988.

PORRO, R. Educazionescolastica e sistema dei media, en CRESPI, Franco: Sociologia e Cultura: nuovi paradigmi teorici e metodi di ricerca nello studio dei processi culturali, Franco Angeli, Milano,1989.

ROBERTS, D., y SCHRAMM, W. Children's learning from the mass media, en SCHRAMM W., y ROBERTS, D. The Process and Effëcts of Mass

Communication, University of Illinois Press, Chicago, 4a ed., 1977.

SECCO, L. La pedagogia di fronte ai mass media, en MARTELLI, S.:

Videosocializzazione. Processi educativi e nuovi media, Franco Angeli, Milano, 1996.

SOUSA, M.W. de. Jovens e a telenovela: seduções da vida cotidiana, en

PACHECO, E. Dias: Comunicação, Educação e Arte na Cultura Infanto-Juvenil, Loyola, São Paulo, 1991.

THORBURN, D. Television melodrama, en NEWCOMB, H.: Television: the critical view, Oxford University Press, New York, 1987.

TRAQUINA, N. Tendências da televisão portuguesa na nova era da concorrência, en INTERCOM, vol. XX, n¹, 1997.

TURNER V. Dal Rito al Teatro, Il Mulino, Bologna, 1986.

WILLIAMS, R. Televisione. Tecnologia e forma culturale, De Donato, Bari, 1981. 